\title{
A Penny for Your Thoughts: Can Participation in a Student-Industry Conference Improve Students' Presentation Self-Efficacy and More?
}

\author{
Brett Freudenberg, Griffith University, Queensland, AUSTRALIA \\ Mark Brimble, Griffith University, Queensland, AUSTRALIA \\ Victoria Vyvyan, Griffith University, Queensland, AUSTRALIA \\ David Corby, Griffith University, Queensland, AUSTRALIA
}

\begin{abstract}
Success in a modern world requires more than just technical skills, with employers requiring graduates with a range of skills which can be critical for job performance and career advancement (Cohen, 1999; Tucker \& McCarthy, 2001). An important graduate attribute is good communication skills (Usoff \& Feldmann, 1998), with self confidence a key in its development (Reinsch \& Shelby, 1996). The literature also demonstrates that the use of professionals and industry representatives can enhance students' confidence and their self-belief (Subramaniam \& Freudenberg, 2007). It is on the basis of these findings that a full day Student-Industry Conference involving first to third year students in a number of related undergraduate financial planning courses was developed. The conference provided opportunities for these students to come together and present research papers that they had worked on in their courses. These student presentations were attended by not only other students, but also industry representatives who were involved in the assessment process. Furthermore, students had the opportunity to listen to a number of relevant industry speakers on current topics and research in the field. This also included discussions about the overall direction of the industry and the graduate recruitment process. Through this and other mechanisms, the Student-Industry Conference was designed to allow for the improvement of students' selfefficacy through mastery, modelling and verbal persuasion. This paper details the empirical evidence as to whether students' participation in this Student-Industry Conference improved their self-efficacy, particularly in terms of their communication skills. Data from a questionnaire of participating students indicates that the students perceived greater self-efficacy as a result of this initiative. With such improved self-efficacy students may be able to enhance their careers in the future.
\end{abstract}

Keywords: Work Integrated Learning, Self-Efficacy, Student Learning

\section{Introduction}

I N TERMS OF students' education at universities there has been debate about what skills and knowledge that should be taught. This has seen calls for a change in business education to redirect the focus from technical orientation to a conceptual orientation and skills based curriculum (Tan \& Veal, 2005, p 28). While employers believe that universities do provide a 'strong knowledge base' for their students, there is concern about whether the students are equipped with the ability to intelligently apply that knowledge in a work context (Business, Industry and Higher Education Collaboration Council, 2007, p 2).

The importance of this 'workplace application' is critical as numerous reports have recognised that a strong disciplinary knowledge does not of itself guarantee a graduate job (Crebert et al., 2004, p 148; Business/Higher Education Round Table, 1991, 1992, 1993; Association of Graduate Recruiters, 1993, 1995; Sausman \& Steel, 1997; Coopers \& Lybrand, 1998 \& AC Nielsen Research Services, 2000). Graduate skills demanded by employers include being confident communicators, team players, critical thinkers, problem solvers and having initiative (Harvey et al., 1997). Employability skills have been articulated into the eight skills of communication, teamwork, problem solving, self-management, planning and organising, technology, life-long learning, initiative and enterprise (DEST, 2002). However, it is argued that a key determinative of students being able to develop these skills is students' self-efficacy. That is, students' belief about their personal capabilities (Bandura, 1977). For example self confidence has been identified as critical in the development of students' communication skills (Reinsch \& Shelby, 1996).

Drawing upon the research into self-efficacy and influence of work integrated learning ('WIL') experiences, a Student-Industry Conference (the 'Conference') was developed as part of the Financial Planning discipline at an Australian university. It was thought that students' involvement in the Conference would enhance their self-efficacy in terms of their financial planning careers and their presentation and communication skills. This Conference brought together students, academics and industry, and was based on the format of a real life industry conference, 
such as keynote speakers, concurrent sessions and networking activities. However, the innovative learning experience was that students would be presenting their assignments from one of four financial planning courses to an audience of peers, industry representatives and academics. In addition, industry and academic papers were presented that explored the potential for financial planning to influence social justice and welfare in Australia. This enabled students to see both academic and professional aspects of exciting careers within Financial Planning, as well as networking opportunities for future employment. Industry involvement included the assessment of student presentations, presenting papers relevant to financial planning, participation in a careers session and an awards ceremony for outstanding student presentations. Thus the Conference provided an interaction for students which they would not get if they had just attended a normal industry conference.

The Conference aimed to provide students with not only a greater understanding of the industry they were studying, but also opportunities to participate in challenging activities that could improve their self-efficacy, through learning, experience and feedback (Gist \& Mitchell, 1992). Further engagement was anticipated through the incentive that industry representatives would be in the audience and evaluating their presentations. Furthermore, through measuring students' perceived increased self-efficacy due to the Conference, this would help address criticism of little evidence based research which isolates the comparative effectiveness of different strategies in terms of students' employability skills (Business, Industry and Higher Education Collaboration Council, 2007, p 1).

This paper analyses the outcomes of the Conference in terms of whether students' participation improved their self-efficacy, particularly in terms of their communication skills. In addition, we examine whether female student participants exhibit greater self-efficacy growth than their male student participants. We find that the Conference model had a positive impact on both student self-efficacy and communication skills despite students expressing low presentation self-efficacy prior to the Conference. Important parameters of the Conference that appeared to promote these outcomes include industry involvement and students being 'out of their comfort zone'.

The remainder of the paper is structured as follows. The next section discusses the theoretical background that formed the basis of the Conference, followed by a discussion of the Conference format. Before reviewing the results, the research methodologies adopted will be detailed. The final section of the paper will consider the limitations of this study and the potential for future research.

\section{Theoretical Background}

\section{Self-Efficacy}

Self-efficacy has been described as individuals' beliefs, thoughts, and feelings about their personal capabilities (Bandura, 1977, 1986). These beliefs can influence how individuals exercise control over their own level of functioning and, in turn their performance (Bandura, 1977, 1986). Self-efficacy can be considered broadly (generalised) or in task-specific dimensions. While generalised self-efficacy pertains to one's confidence in one's own coping skills which can be manifested in a wide range of challenging situations, task self-efficacy is more domain or context specific (Bandura, 1997). An individual's self-efficacy can be distinguished from the concept of 'self confidence' that relates more closely to a personal predisposition or characteristic dealing with self-worth (Vrugt et al. (1997). The importance of self-efficacy is that an individual's perceptions of self-efficacy can be determinative of an individual's behaviour in a given situation. A person's self-efficacy can be a significant determinant of behaviours such as: achievement strivings, academic persistence and choice of career opportunities, and career competency (Bandura, 1982). More specifically, individual self-efficacy has been found to be positively related to individual performance and satisfaction (Bandura, 1997; Gist \& Mitchell, 1992).

However, other studies have demonstrated a negative relationship with self-efficacy and performance. Studies have found that pessimistic students (students with low self-efficacy) can study harder and thereby have greater improvement on outcomes (Christensen et al., 2002). Conversely, students who have performed poorly may have been too optimistic, leading to inadequate preparation (Christensen et al., 2002). This is similar to prior research that has evidenced negative relationships between self-efficacy and students' performance (Bandura, 1997).

While the effect or influence of self-efficacy can be variable, it is argued that what needs to be addressed are inaccurate perceptions of self-efficacy, and the feeling of inability to develop it. It appears that it is common for individuals to have this inaccurate perception of their self-efficacy (Bandura, 1986). Inaccurate perceptions are a concern, as that can cause avoidance of courses and careers, even though the person may have the capability or skill (Christensen et al., 2002). This is particularly insightful considering conclusions that if individuals continue to participate in challenging activities they can overcome their inhibitions. 
A person's self efficacy is not stagnant, and importantly it can be developed, through the notions of mastery experiences, modelling, social persuasion and physiological states (Bandura, 1982; Gist, 1987; Wood and Bandura, 1989; Chowdhury et al., 2002).

Mastery experiences are seen as the most effective way of developing self-efficacy and occur when a student is given the opportunity of mastering an idea or concept (Chowdhury et al., 2002). Prior studies have used service learning as a form of education to facilitate a mastery experience for students, so students were able to practice the skills they had been taught in the class (Tucker \& McCarthy, 2001). Modelling enhances self-efficacy through observation and social comparison (Tucker \& McCarthy, 2001). Observation provides individuals the opportunity to see how others have managed difficult situations; whereas through social comparison individuals can see similar individuals succeed.

Another way of developing self-efficacy is through social persuasion, which occurs when individuals receive realistic encouragement, and the more credible the source the stronger the development (Wood \& Bandura, 1989). Finally, individuals' self-efficacy can also be developed through increasing awareness of their physiological state when confronted with a task, as they may interpret this as a predicator for poor performance. If individuals can modify their physiological state, for example by reducing stress levels, self-efficacy may be increased (Wood \& Bandura, 1989).

\section{Self-Efficacy and WIL}

By participating in a WIL programme, students could be given the opportunity to develop and better understand their self-efficacy. WIL programmes have been used to develop students' competences (Arnold et al., 1999), and prior studies indicate substantial personal development by students who participate in such programmes (Day et al., 1982). Prior WIL programmes have demonstrated increases in job knowledge and skills, and importantly improved attitudes and behaviours towards work readiness (Hughes and Moore, 1999).

WIL programmes have been commonly described as "educational programs which combine and integrate learning and its workplace application, regardless of whether this integration occurs in industry or in the university and whether it is real or simulated" (Atchison et al., 2002, p. 3). There are a number of possible models for a WIL programme, such as Mentored Employment, University/Industry Research; Supervised Work Experience; Customised Accredited Workplace Learning; Enterprise Development and Entrepreneurial Programs; and Simulations (Atchison et al., 2002). The organisation of the
Conference in an industry format with the involvement of industry participants provided for a 'simulated' WIL experience.

It is argued that a WIL programme can provide a platform for students to develop their self-efficacy skills and thereby lead to the potential for greater achievement. For example students that could both observe and obtain feedback from senior professionals in their field are likely to have significant effect on their self-efficacy and understanding (Coll et al., 2006). This exposure may provide students with a richer understanding of the key attributes of success, and consequently lead to greater self confidence (Harvey et al., 1997). Such a relationship of involvement in a simulated WIL experience for accounting students saw more than half of the respondents indicate a significant or great improvement in self-efficacy (Subramaniam \& Freudenberg, 2007).

An incidental consequence of WIL programmes is that they may improve an individual's self-efficacy when faced with a variety of situations, as they have a history of varied and numerous experiences (Scherer et al., 1982; Chen et al., 2001). Others have also sought to define self-efficacy in terms of work, formulating the term 'work self-efficacy' to mean “one's confidence in executing courses of action in managing a wide array of situations" (Raelin, 2003). The connection with WIL and self efficacy is important as research has found new employees with greater self efficacy may be more self-sufficient and capable of surviving the 'entry experience' (Saks, 1995).

\section{Self-Efficacy and Gender}

Gender has previously been a factor that may affect self-efficacy on certain tasks (Lent et al., 1994). In particular, it is argued that females may have a weaker sense of self-efficacy that they can master the requirements of some traditionally male pursuits such as mathematics (Bussey \& Bandura, 1999) and entrepreneurship (Wilson et al., 2007). In the accounting discipline it has be found that there can be significant differences in certain sub-dimensions of selfefficacy between male and female students, with males demonstrating greater self-efficacy (Subramaniam \& Freudenberg, 2007, p 83).

Financial planning as a profession has, to a large extent, been dominated by men. While there are a number of women entering the financial planning profession, their progression to financial advising roles is not as smooth as it can be for their male counterparts. This may impact females' confidence levels in terms of communication and identity with the profession. For example, the lack of socialisation and other experiences, and the limited number of female role models at senior levels in the financial 
planning industry may work to undermine the selfefficacy of female financial planning students compared to their male counterparts.

\section{Design of the Student-industry Conference}

Reflecting upon the established literature the Conference was organised to develop student's self-efficacy towards financial planning, as well as students' communication skills. This literature influenced the design of assessment items and the actual Conference day, each of which is described below with reference how improvements in self-efficacy were implemented through Mastery, Modelling, Social Persuasion and/or Physiological States.

The Conference was the result of a co-ordinated effort between University staff and industry with the former responsible for the design of the course material and assignments that were to be presented at the Conference and to handle the logistics and administration of the Conference. Critical to the success of the Conference was the involvement of industry to provide the real world, WIL, incentive for students. The Conference itself was designed to reflect professional conferences that students latter in their careers would be likely to attend. This included (a) a registration process with conference program, nametags and bags; (b) industry stands; (c) concurrent sessions; and (d) networking opportunities. The Conference featured a comprehensive program commencing at $8.30 \mathrm{am}$ with the official welcome and closing at $5.30 \mathrm{pm}$, with a networking function following this.

The response from industry was very positive with 16 firms and two industry bodies participating on the day (represented by 40 individuals). These included industry leaders such as Robbie Bennetts, CEO of Professional Investment Services and Neil Kendall winner of Money Management Award for the best financial planner in Australia. Industry participated in the Conference in a number of ways including providing speakers (modelling and social persuasion), assessment of students' oral presentations (mastery and social persuasion), information booths (social persuasion), the presentation of awards (social persuasion), participation in a careers session (modelling and social persuasion) and sponsorship.

Industry speakers provided both modelling and social persuasion through their delivery and topics. For example the topics delivered by industry included the importance of understanding your client, quantitative research and investment strategies, negative geared rental properties, research into tax literacy as a component of financial capability, and "Financial Planning in the future - moving from industry to profession". A careers talk back session also provided modelling and social persuasion with representatives from financial planning firms, recruitment agencies and accounting firms providing students with the opportunity to listen to the careers development of a number of past students, as well as gain an understanding of the graduate recruitment process.

The student presentations (42 in total) had a Chair, and were assessed by an academic and industry representative(s) to standardised criteria. Also the assessment form provided the opportunity for the assessors to nominate outstanding presentations for awards. Each presentation ran for approximately 20 minutes with 10 minutes for question and answer time. For students presenting this allowed for Mastering, Social Persuasion and Physiological states, whereas students in the audience were provided with Modelling.

The Conference also sought to provide particular encouragement to female students through modelling and social persuasion to improve self efficacy. This included a special key note address by a female senior manager of a bank to discuss issues facing women in financial planning, including how to keep your integrity and be promoted. Additionally, many of the topics addressed by students in their presentations address social justice issues, such as looking at financial literacy of young people, and the place of ethics in tax planning.

\section{Assessment}

Student participants of the Conference were enrolled in one or more of a number of core courses in an undergraduate Financial Planning Degree; being (a) Introduction to Financial Planning; (b) Investment Planning; (c) Retirement and Estate Planning; and (d) Tax Planning. The convenors of these courses designed assessment items that could be presented at the Conference. These were either done individually or within groups and each of these assessment items are described below with reference to how they allowed for the development of students' self-efficacy, through mastery, modelling, persuasion and physiological awareness.

\section{Introduction to Financial Planning and Retirement and Estate Planning}

Students enrolled in the first year course, Introduction to Financial Planning, worked in groups with two students enrolled in the third year course, Retirement and Estate Planning, to develop a research report and presentation on a topic of their choice. These topics included consideration of assessment of risk profiles, professional practice in financial planning, financial literacy and superannuation issues. Students in both courses attended a series of common time sessions to develop skills in researching, presentation techniques and group work and communication 
[Mastery, Modelling, Persuasion and Physiological]. Third year students acted as mentors for the first year students, and worked to encourage them, manage the process and facilitate the effectiveness of the group and ensure participation of all group members [Mastery, Modelling, and Persuasion]. The students in the first year course were challenged to present at the Conference, with third year students assisting in their preparation, and in instilling confidence in their mentees [Persuasion]. Students were also assisted in developing confidence and skills in a practice session [Mastery, Modelling, Persuasion and Physiological]. The final outcome of the assessment item included a research report and a reflective diary [Physiological status].

\section{Investment Planning}

With the course Investment Planning students were required to work in a group and examine a scenario about investment product issues pertaining to hypothetical client(s). The circumstances relating to these clients were analysed, suitable investment products examined and recommendations made (including the advantages and disadvantages). The group's recommendation resulted in a report that was presented at the Conference [Mastery and Social Persuasion].

\section{Tax Planning}

In the third year course Tax Planning students based their presentations on an academic paper they had written addressing one of the prescribed topics. This required students to structure an argument based on research and analysis. The topics provided were developed to be topical and engage students and covered such issues as (a) "Salary Sacrificing is tax avoidance", (b) "Ethics has no place in tax planning", (c) "Tax breaks should go to families", (d) "The tax system discriminates against same-sex couples". To assist students in their academic writing and analysis, a number of workshops were conducted in-conjunction with Learning Assistance on essay writing, as well as research [Mastery]. Additionally, students were provided feedback on their draft introduction and references lists prior to submission [Persuasion]. These assignments were then submitted, marked and given back to students prior to their presentations [Persuasion]. Also, to provide students assistance with their oral presentation skills a workshop on 'oral presentation' skills was conducted by LAS, followed by an opportunity a number of days later for students to do a practice presentation [Mastery]. In these practice presentations students were assessed against the assessment criteria by both the lecturer and fellow students, which was used as a basis for feedback [Mastery, Modelling, Persuasion and Physiological].
Through the mechanisms developed in these courses, students were given the necessary skills and support to assist them with the prospect of presenting to their peers and industry at the Conference.

\section{Research Method}

This study employs a survey methodology to examine the impact of the Conference on students' selfefficacy. The instrument was administered at the end of the Conference and all student attendees were asked to participate, resulting in a final sample of 65 students. 127 students attended the Conference; nonrespondents related to students who either had left the venue early, chose not to complete the survey (it was fully voluntary and no incentives were offered), or failed to complete the survey. In addition to surveying students, eleven semi-structured interviews were conducted with students (randomly selected) concerning their overall impression of their experience regarding the Conference. The interviews were transcribed, coded and analysed using NVivo 7 software to identify concepts and categories (Gibbs, 2002).

\section{Survey Instrument}

In formulating the survey instrument to measure students' self-efficacy the prior work which has focused on task-specific as well as generalised self-efficacy was utilised (Bosscher \& Smit, 1998; Chen \& Gully, 1997; Kirk \& Brown, 2003; Subramaniam $\&$ Freudenberg, 2007). General self-efficacy scales have demonstrated valid associations with initiation and persistency in behaviour (Scherer et al., 1982). However, it is argued that task-specific items will better predict individual behaviour at work. For instance, Wang and Richards (1998) provide empirical support indicating that task-specific measures could outperform a general efficacy scale in the prediction of performance on cognitive tasks. Consequently, a 16 item measure of self-efficacy was adopted, comprising both task specific items and of generalised measures (see Table 2 for the measures used). The generalised measures (items \#1 to \#8) were adopted from Chen et al.'s (2001) general scale of self-efficacy. The remaining eight measures (items \#9 \#16) were developed as task-specific items, requiring students to consider their self-efficacy beliefs potentially affected by the Conference. The lead directive for each item was "Having now completed the Student Financial Planning Conference please indicate when compared to the start of the Conference the extent of 'change' in your belief in each of the following:" A five point scale was provide to participants to respond with, where: $1=$ no change and $5=$ great improvement. The survey instrument also included questions on how satisfied students were 
with the Conference overall and demographic questions about participants.

\section{Descriptive Statistics}

Table 1 presents summary descriptive statistics for the sample, illustrating a balanced sample in terms of gender, few international students (which is typical in financial programs given the Australian centric nature of the program with the various legal, tax and regulatory issues), a cluster in the 20-30 year age bracket and slightly more students in the later stages of their program (partly related to the courses involved in the Conference). In terms of work experience, a majority of students had no direct industry experience, however when other work experience is taken into consideration $81 \%$ of students had been exposed to the workforce.

Table 1: Descriptive Statistics

\begin{tabular}{|c|c|c|}
\hline Variable & Factors & Values \\
\hline $\mathrm{N}$ & & 65 \\
\hline \multirow{2}{*}{ Gender } & Male & $50.8 \%$ \\
\hline & Females & $49.2 \%$ \\
\hline \multirow[t]{2}{*}{ Student Type } & Domestic & $89.2 \%$ \\
\hline & International & $10.8 \%$ \\
\hline \multirow[t]{5}{*}{ Age } & $<20$ & $18.5 \%$ \\
\hline & $20-30$ & $55.4 \%$ \\
\hline & $31-40$ & $9.2 \%$ \\
\hline & $>40$ & $9.2 \%$ \\
\hline & Not Stated & $7.7 \%$ \\
\hline \multirow[t]{2}{*}{ Progression } & $<120 \mathrm{CP}$ & $40.0 \%$ \\
\hline & $>120 \mathrm{CP}$ & $60.0 \%$ \\
\hline \multirow[t]{2}{*}{ Work Experience (FP) } & No & $69.2 \%$ \\
\hline & Yes & $30.8 \%$ \\
\hline \multirow[t]{7}{*}{ Other Work Experience } & Business & $33.3 \%$ \\
\hline & Admin & $7.9 \%$ \\
\hline & Education & $1.6 \%$ \\
\hline & Service Industry & $15.9 \%$ \\
\hline & Science and Other & $12.7 \%$ \\
\hline & Public Service & $1.6 \%$ \\
\hline & Not Relevant/Stated & $27.0 \%$ \\
\hline Student Satisfaction & & 4.18 \\
\hline \multirow[t]{3}{*}{ Student Self Efficacy } & All 16 measures & 3.27 \\
\hline & Measures 1-8 & 3.29 \\
\hline & Measures 9-16 & 3.27 \\
\hline
\end{tabular}

This table presents summary descriptive statistics for student participants of a survey on the outcomes of the Student-Industry Conference. The student satisfaction measure is the average score per student across 17 satisfaction measures for the event where 5 is 'excellent' and 1 is 'very poor'. The self efficacy measures relate to 16 measures of student self-reported improvements in self-efficacy as a result of participation in the Conference (eight generalised measures, items 1-8, and 8 task-specific measures, items 9-16). The scores are average student scores across the measures where a 1 is 'no change' and 5 is 'great improvement'.

Preliminary analysis of the Conference outcomes shows that students enjoyed the day with an average score of 4.18 out of 5 (where 1 is 'very poor' and 5 is 'excellent') based on 17 satisfaction measures. This provides a strong initial endorsement of the Conference as a concept and in relation to various other outcomes such as industry interaction, employ- 
ment outcomes, career advice, program engagement and prestige, and general quality of the student learning experience. However, the issue of interest in this paper is the impact of the Conference on student self-efficacy. On this front, initial data suggests the Conference has had some success in improving student self efficacy with an overall average score per student of 3.27 for the sixteen measures of student self-efficacy, where 1 is 'no change' and 5 is 'great improvement'.

\section{Results and Discussion}

Overall, our evidence suggests that the Conference had a very positive effect on both student learning and engagement. Of the surveyed participants $95 \%$ strongly agreed or agreed that overall they were satisfied with the Conference, with $87 \%$ indicating that the idea of having the Conference was good. $79 \%$ of participants strongly agreed or agreed that the Conference was relevant to their vocational/professional needs. In addition, the effort to make the Conference as real as possible appeared to be successful as indicated by survey responses such as:

'it was like a real world conference, the stands (the freebies) and the sessions held. It gave students access to listen to people and interact with people that they would not normally have access to, to assist them in ascertaining whether Financial Planning is for them' (industry respondent).

Both the satisfaction and perceived 'realism' of the Conference, while pleasing, are also important in terms of providing the environment for influencing student self-efficacy.

\section{Survey Evidence}

Summary survey data is presented in Table 2 provides evidence to support the notion that the Conference had a positive impact on student selfefficacy. For each of the 16 factors there is an increasing trend from left to right indicating that more students report an increase in self-efficacy as opposed to those that report no or little change. In fact, for the 16 measures at least $69 \%$ (average of $75 \%$ across the measures) reported at least an average increase in self-efficacy and at least $45 \%$ a significant increase. This represents a strong endorsement of the Conference in terms of students' views on the impact it had on them. The strong outcomes were also consistent across both the generalised and task specific categories of self-efficacy items with $31 \%$ of students on average reporting an average increase with $14 \%$ and $15 \%$ respectively reporting a great improvement.
This suggests that students obtain self-efficacy improvements both in general terms, but also in terms of their career in financial planning.

In terms of the specific items, the one for which students reported the strongest gains was "My confidence that I can perform effectively on many different tasks" with 53\% of students nominating a significant or great improvement in self-efficacy. This is of particular interest and importance given the research of Raelin (2003), Scherer et al (1982) and Chen et al (2001) where self-efficacy is linked to employment through enabling students to manage in diverse circumstances.

The measure "My ability to be clearer when presenting ideas" records the second highest increases (49\%). This is also important given the focus on developing students' presentation skills and confidence as a key generic and professional skill for financial planning professionals to have. This is followed by "My ability to progress through the ranks in my new place of employment" (48\%) which is also seen as important in terms of career direction and fostering student engagement in their studies and profession. This is complimented by the first of the equal fourth highest measures "My ability to be more effective in seeking employment and in job interviews" (47\%) in terms of student engagement and direction, while the other "My ability to do most tasks very well compared to other people" (47\%) also provides an indication of the direct improvement in student participant self-efficacy.

The two measures which received the lowest reported improvements in student self-efficacy were "My belief that I will achieve most of the career goals that I have been able to set for myself" (41\%) and "My certainty that I will accomplish difficult tasks when faced with them" (40\%). These are both interesting; however it is first worth noting the still strong performance of both of these measures; that is there is no 'weak' performing criterion with only a small difference between the highest and lowest. In terms of the former, we suspect that this is due to the students' high expectations that typically see them believing that on the completion of their degree they will be a fully fledged financial planner. Through the discussions with industry participants such expectations will be mitigated and a more realistic transition pathway to industry clarified. The latter, we believe may be driven by the highly technical and ever changing financial planning legislative regime and the increasing sophistication of financial products. The students were exposed to this by several of industry speakers and this complexity for some (particularly the first year students), at least anecdotally, was daunting. 
Table 2: Perceptions of Improvement in Self-Efficacy

\begin{tabular}{|c|c|c|c|c|c|}
\hline \multirow[t]{2}{*}{ Self Efficacy Measure } & \multicolumn{5}{|c|}{ Perceived Improvement } \\
\hline & \begin{tabular}{|l|} 
No \\
change \\
$(1)$
\end{tabular} & $\begin{array}{l}\text { Slight } \\
(2)\end{array}$ & Average (3) & $\begin{array}{l}\text { Significant } \\
(4)\end{array}$ & $\begin{array}{l}\text { Great } \\
(5)\end{array}$ \\
\hline \multicolumn{6}{|l|}{ Generalised Self-efficacy items } \\
\hline $\begin{array}{l}\text { My belief that I will achieve most of the ca- } \\
\text { reer goals that I have been able to set for } \\
\text { myself }\end{array}$ & $11 \%$ & $11 \%$ & $36 \%$ & $36 \%$ & $5 \%$ \\
\hline $\begin{array}{l}\text { My certainty that I will accomplish difficult } \\
\text { tasks when faced with them }\end{array}$ & $19 \%$ & $7 \%$ & $33 \%$ & $33 \%$ & $7 \%$ \\
\hline $\begin{array}{l}\text { My general belief that I can obtain outcomes } \\
\text { that are important to me }\end{array}$ & $13 \%$ & $15 \%$ & $29 \%$ & $29 \%$ & $13 \%$ \\
\hline $\begin{array}{l}\text { My belief that I can succeed at almost any } \\
\text { endeavour to which I set my mind }\end{array}$ & $7 \%$ & $20 \%$ & $31 \%$ & $31 \%$ & $11 \%$ \\
\hline $\begin{array}{l}\text { My ability to overcome successfully many } \\
\text { challenges }\end{array}$ & $5 \%$ & $21 \%$ & $29 \%$ & $29 \%$ & $16 \%$ \\
\hline $\begin{array}{l}\text { My confidence that I can perform effectively } \\
\text { on many different tasks }\end{array}$ & $12 \%$ & $7 \%$ & $29 \%$ & $29 \%$ & $24 \%$ \\
\hline $\begin{array}{l}\text { My ability to do most tasks very well com- } \\
\text { pared to other people }\end{array}$ & $7 \%$ & $19 \%$ & $28 \%$ & $28 \%$ & $19 \%$ \\
\hline $\begin{array}{l}\text { My ability to perform quite well even when } \\
\text { things are tough }\end{array}$ & $10 \%$ & $16 \%$ & $29 \%$ & $29 \%$ & $16 \%$ \\
\hline \multicolumn{6}{|l|}{ Task-specific items } \\
\hline $\begin{array}{l}\text { My confidence in beginning a career in finan- } \\
\text { cial planning }\end{array}$ & $9 \%$ & $20 \%$ & $30 \%$ & $30 \%$ & $11 \%$ \\
\hline $\begin{array}{l}\text { My ability to progress through the ranks in } \\
\text { my new place of employment }\end{array}$ & $6 \%$ & $11 \%$ & $35 \%$ & $35 \%$ & $13 \%$ \\
\hline $\begin{array}{l}\text { My confidence in being able to present finan- } \\
\text { cial planning matters to future clients in an } \\
\text { effective manner }\end{array}$ & $8 \%$ & $13 \%$ & $33 \%$ & $33 \%$ & $12 \%$ \\
\hline $\begin{array}{l}\text { My confidence in being able to present finan- } \\
\text { cial planning matters to future work col- } \\
\text { leagues in an effective manner }\end{array}$ & $12 \%$ & $8 \%$ & $34 \%$ & $34 \%$ & $12 \%$ \\
\hline $\begin{array}{l}\text { My ability to be more effective in seeking } \\
\text { employment and in job interviews }\end{array}$ & $11 \%$ & $16 \%$ & $27 \%$ & $27 \%$ & $20 \%$ \\
\hline My ability to be clearer when presenting ideas & $5 \%$ & $16 \%$ & $31 \%$ & $31 \%$ & $18 \%$ \\
\hline $\begin{array}{l}\text { My confidence in being able to work under } \\
\text { pressure }\end{array}$ & $7 \%$ & $19 \%$ & $29 \%$ & $29 \%$ & $16 \%$ \\
\hline $\begin{array}{l}\text { My confidence in networking with other } \\
\text { professional colleagues }\end{array}$ & $11 \%$ & $20 \%$ & $26 \%$ & $26 \%$ & $17 \%$ \\
\hline
\end{tabular}

This table reports average student responses to 16 self-efficacy criteria across four response options.

Overall, we contend that these results provide evidence that the Conference model does improve student self-efficacy in both general and task specific terms. To further investigate this we provide crosstabulation data that breaks up the sample by gender, age, progression and financial planning work exper- ience against average student self-efficacy score (see Table 3). In terms of gender, while female respondents have a higher number of great improvements ( $12.9 \%$ compared to $9.4 \%$ for males), once the significant improvements are taken into account the male students (59.4\% compared to $37.8 \%)$ appear to report higher gains in self-efficacy. This however, we suggest is only marginally so with $75 \%$ of males report- 
ing at least an average increase and $77.4 \%$ of females. Hence, we conclude both genders report positive self-efficacy impacts from the Conference, with the males slightly more positive on the outcomes on average. This is interesting given the attempts made in the Conference program to encourage female students through modelling and social persuasions discussed earlier in the paper. This suggests that more could be done in this space given the traditionally male dominated financial planning industry.

For students who did not have work experience in the financial planning industry appear to report a higher degree of benefit from the Conference (63.7\% either significant or great compared to $43.2 \%$ for those with industry experience), perhaps indicating that the Conference is making up for a lack of selfefficacy that is developed on the job by their peers who have such experience. This is an interesting finding as it suggests that the Conference model is a genuine work integrated learning experience for students in terms of developing work related skills and confidence.

Table 3: Student Self-Efficacy Scores by Gender, Age, Progression and Work Experience

\begin{tabular}{|l|l|l|l|l|l|}
\hline & \multicolumn{5}{|c|}{ Average Student Self-Efficacy Score } \\
\hline Variable & 1 & 2 & 3 & 4 & 5 \\
\hline Gender & & & & & \\
\hline Male & $6.3 \%$ & $18.8 \%$ & $15.6 \%$ & $50.0 \%$ & $9.4 \%$ \\
\hline Female & $0.0 \%$ & $22.6 \%$ & $38.7 \%$ & $25.8 \%$ & $12.9 \%$ \\
\hline Age & & & & & \\
\hline$<20$ & $8.3 \%$ & $33.3 \%$ & $25.0 \%$ & $25.0 \%$ & $8.3 \%$ \\
\hline $20-30$ & $0.0 \%$ & $17.1 \%$ & $25.7 \%$ & $45.7 \%$ & $11.4 \%$ \\
\hline $31-40$ & $0.0 \%$ & $33.3 \%$ & $50.0 \%$ & $16.7 \%$ & $0.0 \%$ \\
\hline$>40$ & $16.7 \%$ & $16.7 \%$ & $16.7 \%$ & $16.7 \%$ & $33.3 \%$ \\
\hline $\begin{array}{l}\text { Progression through } \\
\text { Degree }\end{array}$ & & & & & \\
\hline$<50 \%$ complete & $8.0 \%$ & $20.0 \%$ & $20.0 \%$ & $44.0 \%$ & $8.0 \%$ \\
\hline$>50 \%$ complete & $0.0 \%$ & $21.1 \%$ & $31.6 \%$ & $34.2 \%$ & $13.2 \%$ \\
\hline $\begin{array}{l}\text { Financial Planning } \\
\text { Work Experience }\end{array}$ & & & & & \\
\hline Yes & $4.5 \%$ & $25.0 \%$ & $27.3 \%$ & $31.8 \%$ & $11.4 \%$ \\
\hline No & $0 \%$ & $10.5 \%$ & $26.3 \%$ & $52.6 \%$ & $10.5 \%$ \\
\hline
\end{tabular}

This table presents cross tabulated data from a sample of student respondents to a survey on their self reported changes in self efficacy as a result of attending a student-industry Conference.

In terms of age and progression, the general pattern continues of more students reporting an increase in self-efficacy than not, however there does not appear to be any pervasive trend within the variables themselves. Students in the earlier stages of their program (completed less than half of the degree) report slightly higher gains in self efficacy $(52 \%$ either significant or great compared to $47.4 \%$ for the later stage students), however again the overall result is positive for both groups.

\section{Interview Evidence}

To further support the survey data in terms of an improvement in self-efficacy, a number of follow up semi-structured student interviews were run with a randomly selected sample of students who participated in the Conference. Broadly, the interview outcomes supported those of the survey, while adding richness to the data in terms of specific feelings and beliefs in terms of the Conference and its outcomes. Overall, students report an improvement in self efficacy as indicated by the following:

"I mean I always think that I'm good but I never think that I'm the best or that sort of thing. But this time I actually did" Interview 3 (M)

Furthermore, a key underlying theme in the interviews is the importance (in terms of the Conference outcomes) of the heavy industry participation. 


\section{Self Efficacy}

In terms of self-efficacy the interviewees report positive outcomes and an increased recognition of self-ability to achieve and that effort will be rewarded:

"I thought that our presentation was really good and it was just nice to think that we did actually do a good job and have a little bit more faith in ourselves" Interview 9 (M)

"I've proved to myself that I can do it if I really want to and that's probably a big thing with most people, it's the mental, if you think you can't do it you'll never be able to do it, because your brain will stop you." Interview 3 (M)

"I guess it has reinforced the fact that I am a reasonably good speaker when it comes to talking in front of people or with people from different levels so it's made me more confident in my own ability." Interview 10 (M)

"it was never a strength of mine, but I have found throughout my life that a lot of things that I thought I was fairly weak at, when you actually make the effort and do it, you realise that you are not so bad and it is another one of those things that helps you learn, like you can achieve anything you want to do if you actually want to put the effort into doing it" Interview 3 (M)

\section{Industry Interaction}

As mentioned above, industry interaction was a key message from the interviews and this appears to have provided the influence of social persuasion. In addition, being able to attend industry talks on industry matters (as opposed to graduate recruitment), presenting in front of industry and peers appears to have instilled greater confidence for students in terms of ex post reflection of their performance and ability to 'hold their own' in the face of such a daunting audience:

"Industry people always come across as being scary but they are not really if you are just standing round at the end and have a couple of drinks and eat stuff, definitely increased my confidence and proved that they are not all big and scary, they are just normal people"

"I guess it was the whole presentation and networking and opportunity within the Conference lifted my self confidence up" Interview $11(F)$ "I think if you can get up and present at that Conference in front of industry representatives you can do anything, it's as simple as that!" Interview $11(F)$

"actually talking to the industry people, because I think they don't expect much from us but when they saw our presentation they were, wow, you did this that's good and they were acknowledging us for that" Interview 2 (F)

\section{Out of their Comfort Zone}

It was also clear from the interviews (and anecdotally leading up to the Conference) that the Conference meant the students had to extend themselves and step outside of their comfort zone. On reflection, the interviewees believe that this in itself led to positive outcomes:

\begin{abstract}
"I think the Conference was more the comfort zone thing in that I was out of my comfort zone in that I was presenting to people in a profession that I want to get into, so it was that side of it. I mean if I didn't have experience in that sort of thing then it probably would have been a great assistance because it builds your confidence. The more strangers that you talk to and present to the easier it gets" Interview 11 (F) "I guess it was the whole presentation and networking and opportunity within the Conference lifted my self confidence up because I hadn't done any presenting for a while and I'd sort of been in a difficult situation for a while so I hadn't been dealing with people from different levels so I guess it has just reinforced the abilities that I had earlier and sort of reignited my self confidence in that area." Interview 10 (M)
\end{abstract}

This appears to support the idea that if individuals continue to participate in challenging activities they can overcome their inhibitions.

\section{Presentation Skills}

In terms of presentation skills the interviewees indicated that their learning was not only restricted to their own presentation, but Modelling was also instructive in terms of their peers and the industry speakers. In addition, students appreciated the link between their theoretical knowledge and being able to present, recognising the higher level of understanding that is required to be able to effectively and confidently present a topic well. Some interviewees have also looked to further develop their presentation skills and have sought out further support for developing these.

"Ok, it has given me more of an understanding, because I have watched so many people of how to do it, how you should do it." Interview $7(F)$ "Just something that you could be proud of, not be embarrassed to be talking about something like really understanding the topic and everything like that." Interview $8(F)$ 
"I think my confidence is based purely on how much I know and how well I know what I'm presenting and with the different presentations that I did on the day there were some that I didn't know that well and there were some that I did know well and it showed me that if I know what I'm talking about I can be a lot more confident in what I'm presenting so I guess confidence is about how much you know what you are talking about" Interview 9 (M)

"because of the Conference I had a look and there are actual presenting workshops that you can go to here at the uni and I didn't realise that there were so I am looking at that." Interview $7(F)$

The receipt of awards or even observing other students receiving them appeared to improve self-efficacy through Modelling and Social Persuasion:

"I think it did have a positive impact in that whilst I'm used to public speaking and doing presentations in public, it's the first time I've actually done a presentation of any type on a financial planning topic and winning a prize on top of that certainly boosted my confidence in that area." Interview 10 (M)

Furthermore, the improvement in self-efficacy in terms of presentation skills appears to be something that students consider will be ongoing:

"I think I will be able to present on a financial planning topic." Interview $2(F)$

"..I thought this is really a good thing and I actually believe now if I actually had to get up and give a presentation in a career it won't worry me anywhere near as much and I'll be a lot better off for it. " Interview 3 (M)

\section{Gender}

For female interviewees an apparent strong influence on their self-efficacy was Modelling, in particularly in seeing female professionals who had progressed in the financial planning industry:

"I come from a very patriarchal society so seeing women in a position of power is very good, it makes me think that yes we are capable of doing more than just being housewives, so that is very good and inspirational" Interview $5(F)$

"Vicki Doyle from Suncorp, yes I liked her speech .... something about her speech struck me" Interview 2 (F)

"I like seeing women doing things empowering women” Interview 2 (F)

\section{Other Observations}

In addition to improvements in self-efficacy, the Conference appears to have a number of other positive outcomes. The notion of presenting in front of industry was daunting for students, which resulted in students at times putting in greater effort into their assessment pieces. Due to this effort, students found the Conference an extremely positive learning experience. In addition, the Conference assisted students in affirming their career choice and the confidence to succeed in it:

"I was always a bit worried that financial planning was a lot smaller than what it is but having a whole bunch of people there from the industry shows that it is pretty big so definitely increased my confidence in being able to find work in financial planning." Interview 9 (M)

"I believe that the student Conference.....was great as it offered me a plan and some advice to use in the future within the financial planning sector."

"The great number of professional people who I was able to ask about things that concerned me in financial planning. More over, till this Conference I wasn't sure about taking financial planning as my future career. But now I think I'm confident about being a financial planner."

The Conference also provided a positive impression of the participants, being students, industry and the university. Students saw the Conference as a highlight of their university careers and saw the participation of industry as recognition of the university's prestige. Industry saw the university as a leader in its field and was impressed by the students' ability. Senior university management were also impressed by the extent of the interaction with students and industry, and the academic staff's capability of implementing such an innovative event.

\section{Conclusion}

In 2007, a Student-Industry Conference was run titled: "A Penny for Your Thoughts". This Conference was designed to bring students and industry together for mutual benefit, and in particular to develop the confidence and self-efficacy of students to assist in their technical and skill development as they navigate their way from student to professional. Our analysis of student feedback on the Conference in the form of surveys and interviews appears to suggest that they found the experience instrumental in the improvement of their self-efficacy. In particular, those that had a positive overall experience are more likely to improve their self-efficacy, with male students, 
those in the later stages of their degrees and without relevant work experience benefiting the most.

It appears that the Conference acted as an intervention for students as they were required to present at the Conference as part of their assessment even though they may have low presentation self-efficacy. Such an intervention appears to act as a 'catalyst for change' beyond what they had experienced (Tucker \& McCarthy, 2001, p 242). Such a change will hopefully hold them in good stead as they progress through their studies and into their professional careers.

Accordingly we encourage our peers in tertiary education, in all fields, to consider developing work integrated learning initiatives in collaboration with industry partners such as that discussed here and report of the outcomes of the activity so that we can further develop our understanding of how to develop our students' self-efficacy.

The results of this study, however, should be interpreted with some caution as there are limitations. Primarily, this study is essentially a case study and hence further conference events are needed to determine the generalisability of the results. In addition, self-efficacy improvements were measured on perceived improvement through reflection by the students rather than pre/post and/or control group measures which were not possible for this Conference. Additionally, it would be interesting to interview students later in their careers to see how they perceive the influence of the Conference has played, if any, on their career development.

This paper also provides avenues for further research. For example the conference model could be applied to other disciplines and indeed to further cohorts of students to develop a larger and more diverse sample. Similarly, other disciplines could provide a greater number of international students who have particular skill and self-efficacy issues. Further, more work can be done on our existing data to further examine the characteristics of each of the 16 self-efficacy measures. These, and other areas of further research, will extend the current paper in terms of our understanding of the effectiveness of university-student-industry interactions in terms of the student learning experience, including student self-efficacy.

\section{References}

AC Nielsen Research Services. (2000). Employer satisfaction with graduate skills (Research Report Evaluations and Investigations Programme, Higher Education Division). Canberra: Department of Education, Training and Youth Affairs.

Arnold, J., Loan-Clarke, J., Harrington, A., \& Hart, C. (1999). Students' Perceptions of Competence Development in Undergraduate Business -related Degrees. Studies in Higher Education 24 (1), 43.

Association of Graduate Recruiters, 1993, 1995

Atchison, M., Pollock, S., Reeders, E., \& Rizzetti, J. (2002). Work Integrated Learning Paper: RMIT.

Bandura, A. (1977). Self-efficacy: Toward a unifying theory of behavioral change. Psychological Review, 84(2), 191.

Bandura, A. (1982). Self-efficacy mechanism in human agency. American Psychologist, 37(2), 122.

Bandura, A. (1986). Social Foundations of Thought and Action: A Social Cognitive Theory. Englewood Cliffs, NJ: Prentice Hall.

Bandura, A. (1997). Self Efficacy: The Exercise of Control. New York, NY: WH Freeman.

Bosscher, R.J., \& Smit J.H. (1998). Confirmatory factor analysis of the general self-efficacy scale. Behaviour Research \& Therapy, 36(3), 339.

Business/Higher Education Round Table. (1991). Aiming higher (Commissioned Report No 1). Melbourne, Australia.

Business/Higher Education Round Table. (1992). Educating for excellence (Commissioned Report No 2). Melbourne, Australia.

Business/Higher Education Round Table. (1993). Graduating to the workplace: Business students' views about their education (Commissioned Report No 3). Melbourne, Australia.

Business, Industry and Higher Education Collaboration Council. (2007). Graduate Employability Skills: Prepared by Precision Consultancy. Barton

Bussey, K., \& Bandura, A. (1999). Social cognitive theory of gender development and differentiation. Psychology Review, $106,892$.

Chen, G., \& Gully, S.M. (1997). Specific self-efficacy, general self-efficacy, and self-esteem: Are they distinguishable constructs? Paper presented at the 57th Annual Meeting of the Academy of Management, Boston.

Chen. G., Gully, S.M., \& Eden, D. (2001). Validation of a new general self-efficacy scale. Organizational Research Methods, 4(1). 62 .

Chowdhury, S, Endres, M., \& and Lanis, T.W. (2002). Preparing Students For Success in Team Work Environments: The Importance Of Building Confidence. Journal of Managerial Issues, 14(3), 346.

Christensen, TE, TJ Fogarty, and WA Wallace. (2002). The Association between the Directional Accuracy of Self-Efficacy and Accounting Course Performance. Issues in Accounting Education 17 (1):1

Cohen, A. (1999). Turnover among professionals: A longitudinal study of American lawyers. Human Resources Management Journal, 38, 61-75.

Coll, R.K. \& Zegwaard, K.E. (2006). Perceptions of desirable graduate competencies for science and technology new graduates. Research in Science and Technological Education, 24(1), 29-58. 
Coopers \& Lybrand. (1998). Skills development in higher education. London.

Crebert, G., Bates, M., Bell, B. Patrick, C-J., \& Cragnolini, V. (2004). Developing generic skills at university, during work placement and in employment: graduates' perceptions. Higher Education Research and Development, 23(2), 147.

Day, J., Kelly, M.J., Parker, D. \& Parr, M.F. (1982). The role of industrial training in business studies sandwich degrees. Business Education, Summer, 105.

DEST. (2002). Employability skills for the future, a report by the Australian Chamber of Commerce and Industry and the Business Council of Australia for the Department of Education, Science and Training, Canberra.

Gibbs, G.R. (2002). Qualitative Data Analysis: Explorations with Nvivo. Buckingham: Open University Press.

Gist, M.E. (1987). Self-Efficacy: Implications for Organizational Behavior and Human Resource Management. Academy of Management Review, 12(3), 472.

Gist, M.E., \& Mitchell, T.R. (1992). Self-efficacy: A theoretical analysis of its determinants and malleability. Academy of Management Review, 17, 183

Harvey, L., Moon, S., \& Geall, V. (1997). Graduates' work: Organisational change and students' attributes. Centre for Research into Quality. Retrieved 1 August 2006 from http:// www.uce.ac.uk/crq/publications/gw/gwcon.htsn

Hughes, K.L. and Moore, D.T. (1999). Pedagogical Strategies for Work-Based Learning New York. Columbia Teachers College, IEE Working Paper No. 12.

Kirk, AK. \& Brown, D. F. (2003). Latent constructs of proximal and distal motivation predicting performance under maximum test conditions Journal of Applied Psychology. 88(1). 40-49.

Lent, R.W, Brown, S.D. \& Hackett, G. (1994). Toward a unifying social cognitive theory of career and academic interest, choice and performance. Journal of Vocational Behaviour, 45, 79.

Raelin, J. (2003). Validating a New Work Self-Efficacy Inventory: Center for Working and Learning, Northeastern University.

Reinsch, L. (Jnr) \& Shelby, A.N. (1996). Communication Challenges and Needs: Perceptions of MBA Students, Business Communication Quarterly, 59(1), 36-51.

Sausman, C., \& Steel, J. (1997). The contribution of graduates to the economy (Report No 7 of the National Committee of Inquiry into Higher Education). London:HMSO.

Saks, A.M.(1995). Longitudinal field investigation of the moderating and mediating effects of self-efficacy on the relationship between training and newcomer adjustment, Journal of Applied Psychology, 80, 211-225.

Scherer, M., Maddux, J.E., Mecandante, B., Prentice-Dunn, S., Jacobs, B., \& Rogers, R.W. (1982). The self-efficacy scale: Construction and validation. Psychological Reports, 51, 663.

Subramaniam, N, and B Freudenberg. (2007). Preparing accounting students for success in the professional environment: enhancing self-efficacy through a work integrated learning program. Asia-Pacific Journal of Cooperative Education $8(1): 77$

Tan, L. M. \& Veal, J. (2005). “Tax Knowledge for Undergraduate Accounting Majors: Conceptual v Technical.” eJournal of Tax Research 3(1): 28.

Tucker, M.L., \& McCarthy, A.M. (2001). Presentation Self-Efficacy: Increasing Communication Skills Through ServiceLearning. Journal of Managerial Issues, 13 (2), 227.

Usoff, C, and D Feldmann. (1998). Accounting Students' Perceptions of Important Skills for Career Success. Journal of Education for Business 73 (4):215.

Vrugt, A.J., Langereis, M.P., \& Hoogstraten, J. (1997). Academic self-efficacy and malleability of relevant capabilities as predicators of exam performance. Journal of Experimental Education, 66(1), 61-72.

Wilson, F, J Kickul, and D Marlino. (2007). Gender, Entrepreneurial Self-Efficacy, and Entrepreneurial Career Intentions: Implications for Entrepreneurship Education. Entrepreneurship Theory and Practice May:387-406.

Wood, R., \& Bandura, A. (1989). Social Cognitive Theory of Organizational Management. Academy of Management Review, 14(3), 361.

\section{About the Authors}

Brett Freudenberg

Brett Freudenberg is a currently a Lecturer at the Griffith Business School within the Department of Accounting, Finance and Economics at Griffith University (Australia). In addition to his taxation teaching, Brett is enrolled in a PhD focusing on Tax Transparent Companies. In 2006 Brett received the Fulbright Award, which saw him conduct research at the University of Illinois to analyse the proliferation of new business forms in the United States and their potential for application to Australian businesses. Brett has received a number of teaching accolades. In 2007, he was part of a team that was awarded Griffith University's "Excellence in Teaching for Programs that Enhance Learning Category"; and individually Brett received a "Certification of Commendation for Excellence in Teaching". Previously, in 2005 he was jointly awarded a Griffith Business School Teaching Citation and in 2003 Brett received the Early Career Award for Teaching Excellence from Griffith University. He has pursued the scholarship of learning and has presented his research at number of teaching conferences, as well as publishing in refereed teaching journals. Prior to commencing with Griffith University, Brett was a senior taxation consultant with KPMG and a solicitor with Corrs Chambers Westgarth. 
Dr. Mark Brimble

Griffith University, AUSTRALIA

Victoria Vyvyan

Griffith University, AUSTRALIA

David Corby

Griffith University, AUSTRALIA 